\title{
Life is but a dream: navios fantasmas e comunidades incomuns em Opisanie świata
}

\author{
Life is but a dream: ghost ships and uncommon communities in Opisanie świata \\ Veronica Antonine Stigger \\ Fundação Armando Álvares Penteado. São Paulo, São Paulo, Brasil.
}

\begin{abstract}
Resumo: Este ensaio visa refletir sobre minha própria produção ficcional, tendo como fio condutor a noção de "comunidades incomum", tema do encontro da APSA em 2016, onde originalmente apresentei este texto como um dos keynotespeakers do evento. A ideia é centrarme no romance Opisanie świata, publicado em 2013, e examinar como os personagens ali constituem o que poderíamos chamar não tanto uma comunidade incomum, mas uma comunidade de incomuns, uma comunidade que tem como único ponto de contato o fato de todos estarem em trânsito, isto é, de todos estarem fora de seus lugares de origem. Ou seja, aquilo que os aproxima não é algo da ordem da identidade, mas do não-pertencimento.
\end{abstract}

Palavras-chave: comunidades incomuns; estrangeiro; Opisanie świata.

\begin{abstract}
This essay aims to examine my own fictional production, having as a guide the notion of "uncommon communities", theme of the APSA congress in 2016, where I originally presented this text as one of the keynotespeaker of the meeting. The idea is to analyze how the characters of the novel Opisanie świata constitute what we can call a community of uncommons, instead of an uncommon community. A community of uncommons has as its sole point of contact the fact that everyone is in transit, i. e., that everyone is out of their place of origin. That is to say that what brings them together is not something of the order of identity, but of the order of non-beloning.
\end{abstract}

Keywords: uncommon communities; foreign; Opisanie świata.

Em 2013, publiquei minha primeira narrativa mais longa, o romance intitulado Opisanie świata. Já havia publicado outros sete livros, sendo dois deles infantis. Fazia anos que trabalhava na elaboração do romance, desde, pelo menos, 2006. Ao longo desses anos, a história foi se montando por camadas. Primeiro, decidi que seria uma narrativa que começaria na Polônia e terminaria na Amazônia brasileira - uma narrativa, portanto, de viagem. Queria que o percurso fosse longo. Pegar um avião na Polônia e, no dia seguinte, chegar à Amazônia não me parecia uma viagem longa o suficiente. Talvez por isso tenha optado por deslocar a ação para o passado, para as primeiras décadas do século $\mathrm{XX}$, quando se levava bem mais tempo para cruzar o oceano Atlântico. O que planejava fazer, sintetizei em três versos que fiz migrar para o romance em forma de anotações encontradas num caderno: "Fazer um livro antigo / um livro de viagens / com páginas que se desdobram" (STIGGER, 2013, p. 139). Com o passar do tempo, precisei o ano em que se passava a história: 1939, às vésperas do princípio da Segunda Guerra Mundial, que é, como todos sabemos, deflagrada com a invasão da Polônia, de onde a narrativa parte. Depois, imaginei o protagonista: Opalka, um polonês de uns sessenta anos, circunspecto, que sairia de Varsóvia rumo à selva amazônica. Não era minha ideia que esta fosse sua primeira incursão pela floresta brasileira, mas, sim, uma viagem de volta depois de muitos anos longe, com tudo o que uma viagem como esta implica: recordações, ausências, reencontro com o passado, na medida em que este reencontro se constitui também como um confronto com o passado: confronto em seus múltiplos sentidos de ficar de frente, de cotejar e, talvez principalmente, de enfrentar, de se bater com. Queria que, quando partisse da Polônia, se Opalka não 
soubesse, que pelo menos pressentisse, que a Amazônia que ele conhecera nos primeiros anos do século $\mathrm{XX}$ não seria mais a mesma que encontraria no final da década de 30. E isso acaba ocorrendo. Cito o momento do livro em que ele chega a Manaus:

\begin{abstract}
A picape se deslocava aos solavancos pelas ruas esburacadas. Opalka olhava distraído pela janela. Não reconhecia a cidade que cogitou adotar como sua há trinta e cinco anos. Estava tudo mudado. Não tanto os prédios e as outras construções, que ainda eram os mesmos, mas tudo o mais. A cidade tinha perdido o brilho de antigamente. Estava opaca. As pessoas andavam mais encurvadas e tristes. Caminhavam de cabeças baixas, olhando para o chão, para o granito das calçadas, antes tão novo, agora mal cuidado e quebradiço (STIGGER, 2013, p. 126).
\end{abstract}

Jean-Pierre, personagem que é responsável por recebê-lo, apenas confirma o que Opalka enxerga:

- Isso aqui já foi grande - disse Jean-Pierre percebendo que Opalka observava a cidade. - Mas agora não é mais. Quando cheguei aqui, ela era puro movimento. Tinha gente de toda parte. O senhor deve saber disso, porque, pelo que Natanael me contou, o senhor esteve aqui quando a cidade estava no auge. Não foi? Mas isso é passado. A cidade hoje está morta (STIGGER, 2013, p. 126-127).

A impossibilidade de se reencontrar e recuperar o passado, que é sempre e por princípio inatingível, se cifra no livro na impossibilidade de Opalka reconhecer, na cidade do presente, aquela cidade em que vivera décadas atrás e que acreditava tê-la compreendido - friso "acreditava" porque talvez nunca compreendamos de todo uma cidade, nem mesmo aquela em que nascemos e crescemos; que dirá uma cidade outra, pertencente a uma cultura estranha e diversa à cultura em que fomos criados. Depois de tantos anos afastado, a cidade estrangeira que Opalka "cogitou adotar como sua" não lhe é mais familiar. Ela não existe mais. Tornou-se ficção, que é, em certa medida, o que ocorre com o passado, se pensarmos que reconstituir a memória do que passou é buscar dar coerência ao que nos chega de forma incoerente e fragmentada; é, em outras palavras, preencher as lacunas, criar narrativas para suprir as faltas.

Se, por um lado, em Opisanie świata, o passado se revela inatingível e irrecuperável, por outro, o futuro tampouco se mostra mais acessível. Jean-Pierre, um pessimista inveterado, depois de mostrar como a Manaus presente não guarda mais nada da Manaus passada, alerta Olpaka: "O senhor vai ter que se acostumar com isso". Por quê, poderíamos nos perguntar? É o próprio JeanPierre quem explica:
Porque o senhor sabe que não poderá voltar, pelo menos, não por agora, não sabe? O senhor ouviu as últimas notícias? A Polônia acabou. Anunciaram hoje. Acabou. Foi tomada. Daqui a pouco, toda a Europa não vai existir mais, se é que ainda existe. O negócio é ficar por aqui mesmo. Aproveitar, antes que a cidade morra de vez, para sempre. Aqui pelo menos é quente. Não faz aquele frio medonho da Europa. E tem verde. Um verde lindo. Pena que tudo isso um dia vai acabar também (STIGGER, 2013, p. 126-127).

A posição de Jean-Pierre, no final do livro, se contrapõe, em certa medida, à visão de outra personagem, quase uma aparição, uma senhora bem pequena, muito magra e muito enrugada, vestida com roupas masculinas e com uma barbicha no queixo, que, logo no início da narrativa, faz um elogio à viagem, mas frisa a necessidade de se retornar ao lugar de origem: "[...] é preciso voltar. Fique um ano, dois, três. Mas volte. Vá e volte. É preciso saber voltar" (STIGGER, 2013, p.42). O que a senhora, naquele momento inicial da história, esquece de mencionar é a impossibilidade de voltar. Impossibilidade esta que acaba soando como um baixo contínuo ao longo de todo o livro, mas que soa mais alto e mais potente nos capítulos finais. Para quem como eu saiu de sua cidade de origem e adotou uma outra cidade para viver, sabe que é impossível voltar: a Porto Alegre que deixei em 2001 para viver em São Paulo não existe mais. Como a Manaus que Opalka encontra trinta e cinco anos depois, tudo está mudado. Se resta algo da arquitetura a partir da qual ainda posso reconhecer a cidade em que nasci e vivi até os 28 anos, tudo o mais desapareceu.

Mas voltemos ao que vinha dizendo anteriormente. Imaginei que Opalka, o protagonista, não empreenderia uma viagem de descoberta da Amazônia, mas de retorno, portanto, de redescoberta. Para empreender a viagem de regresso, ele precisava ter um motivo. Pelo menos, assim eu achava. Foi aí que imaginei (e criei) o filho, Natanael, um filho que ele não sabia existir e que, muito doente, lhe escrevera pedindo para conhecê-lo. Eu não queria que Opalka realizasse esta travessia sozinho. Daí criar também Bopp, um turista e poeta brasileiro, livremente inspirado no escritor Raul Bopp, um personagem amoroso e extravagante, que Opalka conhece logo no início da viagem e que decide acompanhá-lo até o destino final. Queria ainda que a maior parte da narrativa se desenrolasse durante o percurso e que Opalka e Bopp fossem encontrando as mais diferentes pessoas pelo caminho. Por isso, aparecem ainda na história o russo grosseiro e maleducado que insiste em abrir uma janela emperrada; a italiana Priscila Antonini, que é mordida por uma aranha e cai no chão dançando e se contorcendo; as andaluzas Dona Oliva e as Olivinhas, suas castas sobrinhas; o senhor e a senhora Andrade, antigos reis do café em São Paulo; 
o uruguaio Curto Chivito e seu companheiro alemão Hans; Amado Silva, médico de Natanael; o empresário francês Jean-Pierre e suas quatro Clodiás (uma francesa, uma oriental e duas índias); as crianças, os cachorros e cerca de meia dúzia de assombrações. E assim acabou se constituindo uma pequena comunidade em Opisanie świata.

Mas que tipo de comunidade se formou aí? No livro, com exceção de dois personagens, todos os outros são estrangeiros - estrangeiros porque se acham deslocados de seus lugares de origem. Estão em trânsito. Reparem que eles provêm das mais diferentes partes do mundo: Brasil, Uruguai, Espanha, Itália, França, Alemanha, Rússia, Oriente. Não por acaso, um dos personagens, Curto Chivito, "aposta no desenvolvimento da indústria do turismo" e sonha fundar, "num puxadinho que está construindo no quintal de sua casa, na estrada entre Montevidéu e Colônia do Sacramento", o Museu do Homem em Trânsito com os objetos que ele surrupia dos navios (STIGGER, 2013, p. 73). Os personagens de Opisanie świata constituem o que poderíamos chamar uma comunidade incomum, ou, reformulando, uma comunidade de incomuns, uma comunidade que tem como único ponto de contato o fato de todos estarem em trânsito, de todos estarem fora de seus lugares de origem. Pensando melhor, talvez fosse mais preciso falar de uma comum incomunidade em relação a eles, já que aquilo que os une, que os aproxima, é o não-pertencimento. Eles acabam formando "a comunidade dos que não têm comunidade", como propunha Bataille, segundo a interpretação de Blanchot (1983, p.9). E o leitor não se furta a esta comum incomunidade. Ao dar ao livro um título em polonês, língua do protagonista da história, queria justamente colocar o leitor, nem que fosse por um breve instante, nessa posição de deslocado, ou, antes, revelar a posição de deslocado que, na realidade, é a do leitor desde sempre, mesmo que ele não perceba. Quando escolhi sair de minha cidade natal, para a qual, como já disse (e aqui retomo o que vinha falando), já é impossível voltar, percebi que somos todos estrangeiros. Afinal, não podemos perder de vista que o ser estrangeiro não é uma condição fixa; muito pelo contrário, é variável. E essa variabilidade depende do lugar onde o indivíduo se encontra. Em princípio, podemos notar que a noção de estrangeiro pressupõe a - no sentido de que ela se contrapõe à - noção de nacional, ou seja, a noção de estrangeiro pressupõe a noção de que alguém pertence a uma nação. É estrangeiro aquele que não pertence à nação na qual se encontra num dado momento - o momento em que podemos afirmar a respeito desta pessoa: ela é estrangeira, ou a respeito de nós mesmos, eu sou estrangeira. Fora do Brasil, sou estrangeira. No Brasil, sou brasileira. Em Porto Alegre, sou gaúcha. Em
São Paulo, sou, em certa medida, estrangeira, porque não sou paulista, mas gaúcha. E, quando volto a Porto Alegre e minha família brinca me chamando de "paulista" por estar há muito tempo morando fora da cidade, sou estrangeira. Quando vou comer em algum restaurante do bairro Liberdade, em São Paulo, que é uma espécie de Chinatown, e, à minha volta, estão falando chinês, japonês, coreano ou qualquer outra língua que não domino nem mesmo o alfabeto, língua que costuma ser a do cardápio e também da atendente, eu sou a estrangeira, mesmo estando na "minha nação". Por isso tudo, creio que estar em trânsito, estar em deslocamento, talvez seja a condição definidora do homem moderno. Se existe algo como uma condição humana, ela não se define pelo pertencimento, mas, ao contrário, pelo estranhamento. Ao dar um título em polonês ao meu primeiro romance, queria lembrar o leitor que, a qualquer momento, ele também pode estar na posição de estrangeiro. Mas, vocês podem me perguntar, e se um polonês depara com o título Opisanie świata, o jogo não fica comprometido? Não por muito tempo, porque, ao abrir o livro que, em princípio poderia parecer familiar ao leitor polonês, ele notaria que, com exceção de uma ou outra imagem com dizeres em alemão e em inglês, o resto está todo escrito em português - uma língua bem diversa de sua língua materna - e passaria então a ser estrangeiro diante dele. Não há como resistir a citar aqui, a propósito disso, um autor de que gosto muito, Roberto Bolaño, escritor chileno que passou boa parte de sua vida morando no México e na Espanha. Num belíssimo depoimento, Bolaño afirma: "Toda literatura leva em si o exílio, tanto faz se o escritor tenha tido de ir embora aos vinte anos ou se nunca tenha saído de sua casa" (2006, p. 49). Dado, diz ele ainda, que "os primeiros exilados de que se tem notícia foram Adão e Eva", pergunta-se: "não seríamos todos exilados? não estaremos todos vagando por terras estrangeiras?" (BOLAÑO, 2006, p. 49).

Em Opisanie świata - que, diga-se de passagem, quer dizer "descrição do mundo" e é como se traduz Il Milione, o livro de viagens de Marco Polo, para o polonês -, não são apenas os personagens que se acham na posição de deslocados, de estrangeiros. O próprio Brasil é visto como que pelo olhar de um estranho. No início da viagem, quando Bopp descobre que Opalka está indo para a Amazônia, lhe dá, de presente, um guia, o clássico The South American Handbook, em sua versão de 1934, que apresenta a América Latina para o viajante europeu, em especial, o viajante inglês, como se pode perceber claramente nesta passagem: "O chá da tarde, / feito como deve ser feito, / pode ser encontrado em todas as principais cidades" (STIGGER, 2013, p.68). Apropriei-me de fragmentos deste guia, retrabalhei-os, transformando-os em tercetos, e espalhei-os ao longo do livro. $\mathrm{O}$ único trecho que não se tornou um terceto é a 
tentativa de desfazer a visão de que a América Latina é apenas selvagem e exótica:

É difícil fazer as pessoas entenderem que é possível viajar com o máximo de conforto e segurança nas áreas mais desenvolvidas do continente sul-americano. Os serviços ao longo das rotas mais frequentadas são tão bem organizados quanto os da Europa. Há hotéis de primeira classe em todas as principais cidades, decorados com o costumeiro refinamento moderno. As viagens por vapor, trem ou avião podem ser tão luxuosas na América Latina quanto em qualquer outro lugar no mundo. Mesmo ao longo das rotas menos conhecidas, os eventuais toques primitivos servem para acentuar o prazer do visitante e não para interferir em seu conforto (STIGGER, 2013, p. 45).

É a partir deste olhar exterior que a América Latina em geral e o Brasil em particular é visto no livro, como podemos perceber nas passagens que retrabalhei e incluí em Opisanie świata. Cito aqui algumas delas: "Não há razão para temer doenças. / As áreas temperadas na América Latina / são quase tão sadias quanto a Inglaterra" (STIGGER, 2013, p. 87). Ou: “É aconselhável não beber a água dos países sul-americanos. / Não que ela seja invariavelmente ruim. / Mas pode ser" (STIGGER, 2013, p. 70). Ou ainda: "Manaus faz lembrar o Oriente: por toda parte, mendigos / exibindo suas deformações, crianças nuas e remelentas / e altas e portentosas palmeiras ondulantes" (STIGGER, 2013, p. 129). E há também dicas mais práticas: "Não há necessidade de levar armas de qualquer tipo. / Nem mesmo as de fogo. / Aliás, convém evitá-las" (STIGGER, 2013, p. 59). Ou: "Não use chapéu de explorador. / O uso de um deles por um estrangeiro / cria má impressão nos brasileiros" (STIGGER, 2013, p. 118). Ou esta, que, em função da proliferação da dengue, zika e chicungunya no Brasil, todas essas três doenças contraídas por mosquito, convém seguir ainda nos dias de hoje: "Contra mosquitos: luvas para proteger as mãos, / sapatos de cano alto para as canelas / e um véu para o rosto e o pescoço" (STIGGER, 2013, p. 115).

Mas voltando à comunidade de incomuns de Opisanie świata, depois de ter criado aquela série de personagens, que, como destaquei, é, em sua imensa maioria, de estrangeiros, de pessoas diferentes entre si, precisava criar ainda um lugar em que esta comunidade se encontraria, um lugar que fosse tão deslocado e tão em trânsito quanto eles. O primeiro destes lugares de encontro é a estação de trem, que apenas anuncia o início da viagem, onde Bopp aborda Opalka. O segundo é o trem, onde Opalka e Bopp, que já formam uma dupla, dividem a cabine com o russo e Priscila. Mas é no terceiro destes lugares que quero me deter nesta parte final deste ensaio: o terceiro lugar de encontro da comunidade de Opisanie świata é o navio, o espaço heterotópico por excelência segundo Foucault:
E se considerarmos que o barco, o grande barco do século XIX, é um pedaço de espaço flutuante, lugar sem lugar, com vida própria, fechado em si, livre em certo sentido, mas fatalmente ligado ao infinito do mar e que, de porto em porto, de zona em zona, de costa a costa, vai até as colônias procurar o que de mais precioso elas escondem naqueles jardins orientais [...], compreenderemos porque o barco foi, para nossa civilização - pelo menos desde o século XVI - ao mesmo tempo, o maior instrumento econômico e nossa maior reserva de imaginação. Civilizações sem barcos são como crianças cujos pais não tivessem uma grande cama na qual pudessem brincar; seus sonhos então se desvanecem, a espionagem substitui a aventura, e a truculência dos policiais, a beleza ensolarada dos corsários (FOUCAULT, 2013, p. 30).

O navio é o que Foucault chama de "contraespaço", uma "utopia situada", um desses "lugares reais fora dos lugares" (2013, p. 20), que "possuem sempre um sistema de abertura e de fechamento que [o]s isola em relação ao espaço circundante" (2013, p. 26). O navio é, de fato, um lugar fechado, de onde não se sai, até que isso seja permitido; nele, como no avião, estamos numa espécie de sequestro consentido. Quando em alto-mar, isto é, quando em águas que não se encontram sob jurisdição de nenhum Estado, um navio vaga por um não lugar, um u-tópos.

$\mathrm{Na}$ primeira cena dentro do navio, em Opisanie świata, "depois do primeiro jantar a bordo, quando o tédio ainda não tinha se instalado [...] e as pessoas mal se conheciam, cumprimentando-se apenas por educação, longe portanto das futuras e previsíveis efusões de amizade" (STIGGER, 2013, p. 64), Bopp se debruça na amurada e entoa a canção infantil "Row, row, row your boat”. Repete-a duas vezes e, depois, passa a assobiá-la. Os passageiros que estão ali perto começam, aos poucos e timidamente, a acompanhá-lo até que todos juntos a cantam como ela costuma ser cantada: em round. É em torno desta canção que os personagens que irão constituir a pequena comunidade de amigos na embarcação se conhecem e se aproximam. A música fala em conduzir suave e alegremente o barco (a vida?) a favor da corrente. Acreditava que esta canção era perfeita para introduzir a parte do livro que se passaria no navio, onde os personagens que havia criado seriam obrigados a conviver por um bom tempo, ainda mais que se tratava de uma canção cantada em inglês, ou seja, numa língua estranha a todos os envolvidos - o que, parecia-me então, reforçava ainda mais a busca por um comum no incomum. O título do capítulo em que esta cena se passa é "Rema, rema, rema", que corresponde, por um lado, à tradução de parte do primeiro verso de "Row, row, row your boat", mas, por outro, é também o início de um dos versos de uma marchinha popular de carnaval no Brasil, a "Marcha do 
remador"1, que diz: "Rema, rema, rema, remador". E segue com: "Quero ver depressa o meu amor". Versos estes que vêm depois dos que falam: "Se a canoa não virar / Olê, olê, olê, olá / Eu chego lá" — quase uma versão jocosa do "gently down the stream". Confesso aqui que cogitei fazer com que Bopp tentasse traduzir livremente "Row, row, row your boat" para o português e chegasse à "Marcha do remador", criando um anacronismo que me divertia bastante: a "Marcha do remador" é de 1963, de quase três décadas depois de quando se passa a história do livro. Cheguei a esboçar uma versão do capítulo que seguia nesse sentido, em que juntava também os famosos versos "Deixa a vida me levar / Vida leva eu", do samba cantado por Zeca Pagodinho². Mas acabou ficando dispersiva e confusa. Foi então que, depois de enorme relutância, mas com o consolo de que pelo menos a marchinha estaria, de certo modo, sugerida no título do capítulo, desisti da ideia.

Mas ainda não falei do último verso da canção infantil, que, para mim, é fundamental, porque fornece a chave para o que quero expor em seguida: "Life is but a dream". A vida não é mais que um sonho. Se, por um lado, este verso sugere que a vida é curta como um sonho; por outro, sugere também que ela não deixa de ser uma ilusão. Talvez por esta última razão este verso me faz recordar de $A$ vida é sonho, de Calderón de La Barca e do monólogo em que Segismundo se dá conta de que "estamos num mundo tão singular, que o viver é apenas sonhar” e acrescenta ao final (na minha tradução livre):

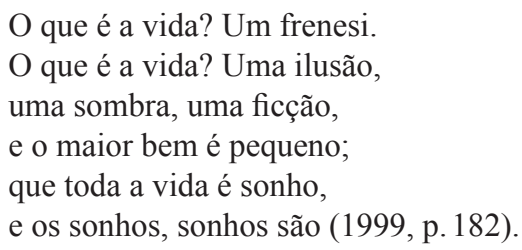

Em Opisanie świata, o navio que conduz aquela incomum comunidade que descrevi anteriormente finge ser, à primeira vista, este lugar sem lugar, que é também um lugar de sonho, em outras palavras, um lugar utópico. No entanto, mais adiante no livro, aparece outro navio que acaba por se contrapor ao primeiro, colocando sua posição em xeque. Ao amanhecer, depois de uma grande festa a bordo, quando a embarcação apenas ultrapassara a linha do Equador, os tripulantes que ainda estavam no convés avistam este outro navio, que navega suave e alegremente pelas águas, levando cerca de 50 passageiros; todos nus. O trecho diz:

\footnotetext{
"Marcha do remador", marchinha de Antônio Almeida e Oldemar Magalães, 1963, gravada por Emilinha Borba.

2 "Deixa a vida me levar", canção de Serginho Meriti e Eri do Cais, 2002. Cantada por Zeca Pagodinho.
}

Nada de panos ou calçados. Nenhum lenço, nenhum chapéu, nenhuma bolsa. Nenhum acessório. Nem maquiagem as mulheres usavam. Muito menos esmalte nas unhas. A única coisa que alguns vestiam eram óculos de grau. E nada mais. Os cabelos se agitavam soltos ao vento em suas cores naturais. Os pelos estavam eriçados com o friozinho que fazia àquela hora da manhã. E eles acenavam, contentes da vida. Vagavam pelos mares sem nunca desembarcar. Viviam do que pescavam. Bebiam água da chuva. E só se banhavam no mar (STIGGER, 2013, p. 113).

O senhor Andrade imediatamente reconhece o navio: trata-se de El Durazno, embarcação que jurava fosse mítica. Sua aparição é uma das tantas evocações e citações literais que faço ao modernismo brasileiro. Neste caso específico, vale ressaltar que quem reconhece o navio como sendo El Durazno é o senhor Andrade, personagem que é uma espécie de pseudo-Oswald de Andrade. Roubei El Durazno de Serafim Ponte Grande e o trouxe para o Opisanie świata. El Durazno é o navio que aparece no capítulo final de Serafim Ponte Grande (romance de Oswald de Andrade), que se intitula "Os antropófagos". Como bem observa Eduardo Sterzi: "Nele [neste capítulo], Oswald apresenta-nos uma imagem antecipadora do 'humano futuro' - da 'humanidade liberada' - na forma de um navio, El Durasno, que vaga de porto em porto, sem que os passageiros, convertidos numa tribo de nus, jamais desembarquem" (2008, p.93-94). Em Opisanie świata, El Durazno se traduz não apenas na imagem do "humano futuro", mas também na do humano passado: "Eles são a humanidade liberada, disse o senhor Andrade para Bopp, com a voz embargada e lágrimas nos olhos, eles são o passado e o futuro" (STIGGER, 2013, p. 113). Ao dizer que eles são o passado e o futuro, o senhor Andrade desloca a possibilidade de encontro com uma "humanidade liberada", com uma humanidade que ali se institui como utópica, para um tempo que não é o presente: para um antes ou para um depois do agora; em outras palavras e retomando o que havia dito no início, para um tempo inatingível. Ou seja, no romance, a utopia termina por se localizar num tempo outro, anterior ou posterior ao presente. Em contraposição a El Durazno, o navio que leva Opalka, Bopp e seus amigos vaga pelo tempo presente, vaga portanto por um tempo simultaneamente pós- e pré-utópico. E o tempo presente, o tempo de agora do navio dos meus personagens, é aquele destituído de esperança, tão bem descrito por Jean-Pierre:

- Ultimamente, tenho pensado muito nesta cidade. No que fazer com esta cidade. O senhor sabe, eu tenho dinheiro. Muito dinheiro. Crio jacarés por hobby, mas estou ganhando uma fábula com a venda destes sapatos abertos. Esse aqui que estou usando, ó. É o mesmo que as Clodiás usam. O Ronaldo aqui - disse ele apontando 
para o jacaré de pelúcia em seu ombro - é meu amuleto. Me dá sorte. É ele que me traz dinheiro, que não me deixa perder um mísero centavo. Com esse dinheiro todo, eu poderia criar um teatro ainda mais bonito que o daqui. Muito maior, mais vistoso, mais rico. Poderia enchê-lo de ouro. Poderia promover festivais de música clássica. Poderia trazer convidados de fora, tenores, sopranos, pianistas. Ou até aquela mocinha do Cassino da Urca, que está fazendo sucesso nos Estados Unidos. Poderia promover festivais de teatro também. Talvez até investir na formação de grupos locais. Criar escolas de música, de belas artes. Trazer muita gente de fora, gente que não vai ter para onde ir agora que a Europa está desmoronando. Poderia construir outras coisas também. Cinemas, talvez. Casas de espetáculos. Poderia montar uma programação para o ano inteiro, para ter uma grande atração a cada semana. Agitar esta cidade, colocá-la no circuito mundial. Fazer dela o grande centro cultural do país, a cidade do futuro. Do futuro. Mas - falou ele por fim, estacionando o carro diante do hospital -, fico me perguntando: pra quê? (STIGGER, 2013, p. 127-128).

El Durazno oferece outra possibilidade de vida. É nele que Foucault encontra Bataille. Não esqueçamos que a ideia de "uma comunidade dos que não têm comunidade" se associa em Bataille ao êxtase, à saída de si. Por isso, em "A conjuração sagrada", ele proclama: "É tempo de abandonar o mundo dos civilizados e sua luz" (BATAILLE, 2008, p. 231). E acrescenta: "Nos mundos desaparecidos, foi possível se perder no êxtase, o que é impossível no mundo da vulgaridade instruída" (BATAILLE, 2008, p. 231). E ainda:

A vida tem sempre lugar num tumulto sem coesão aparente, mas não acha sua grandeza e sua realidade senão no êxtase e no amor extático. Aquele que insiste em ignorar ou em não reconhecer o êxtase, é um ser incompleto cujo pensamento está reduzido à análise (BATAILLE, 2008, p. 231).

Não estaria aí o germe da "humanidade liberada" de Oswald? Não estaria El Durazno desdenhando da nossa humanidade, dessa humanidade que poderíamos chamar controlada? Já notara Sterzi ao se referir ao navio de Serafim Ponte Grande:

Para fugir ao controle de terra (para subtrair-se, nas palavras de Oswald, ao "contágio policiado dos portos"), os embarcados proclamam que há "peste a bordo". Não é outra a mensagem que tanto a comédia quanto a utopia proclamam insistentemente, desde sempre, frente a um mundo controlado (STERZI, 2008, p. 94).

Para Foucault, ao contestar os outros espaços, o navio, como todas as heterotopias, acaba por "cri[ar] uma ilusão que denuncia todo o resto da realidade como ilusão" (2013, p. 28). Em Opisanie świata, a aparição de El Durazno assume este papel: em certa medida, ele lembra que a vida não é mais que um sonho, que é um frenesi, uma ilusão. Dentre todos os personagens do romance, talvez sejam as Olivinhas quem melhor percebam isso. E, para encerrar este ensaio, que foi originalmente fala, gostaria de reproduzir um capítulo do livro, o capítulo que começa justamente com a promessa do êxtase e do amor extático e se intitula "Como soubemos? Fomos até a cozinha".

- Os senhores sabiam que o pessoal da primeira classe faz suruba na cozinha? - perguntaram as Olivinhas a Opalka e Bopp numa tarde em que encontraram os dois sozinhos, tomando sol nas espreguiçadeiras do convés.

Elas falavam ao mesmo tempo, afobadas, uma atropelando a outra. Segundo elas, os passageiros da primeira classe se divertiam bem mais que os da classe turística. Não porque tivessem mais regalias (lençóis de linho, toalhas de algodão felpudo, serviçais para carregar as malas, perfume francês nas cabines, almofadas nas espreguiçadeiras, sobremesa extra), mas porque faziam surubas. Na cozinha. E em qualquer dia da semana. Qualquer. Não respeitavam nem mesmo os dias santos. Passavam as noites lá, se roçando uns nos outros. Um horror. Como elas sabiam disso? Elas tinham ido até a cozinha. Tinham visto tudo com aqueles olhinhos que a terra havia de comer. $\mathrm{Na}$ madrugada de ontem, por volta das duas da manhã, as Olivinhas não estavam conseguindo dormir em função do calor. Aí, elas decidiram fazer um chá para relaxar. Pegaram a chaleira que sempre levavam consigo nas viagens e foram até a cozinha para pedir um pouco de água quente ao cozinheiro. Quando chegaram lá, com a chaleira vazia, deram de cara com dois casais se agarrando. Eles ainda não estavam fazendo sexo, mas quase. A gente sabe quando um casal está quase fazendo sexo, não sabe?, disse a Olivinha de panturrilha mais grossa em tom confessional. Eles ficam assim juntos, bem juntos, acrescentou a outra. Com as pernas enroscadas e... e... as... os...-hesitaram elas, escolhendo a palavra mais adequada - os órgãos genitais roçando. Por cima da roupa, é claro. Porque eles ainda não estavam fazendo sexo. Estavam quase fazendo sexo. Quase. Mas iam chegar lá num instante. Elas não tinham dúvida de que isso iria acontecer. Era só uma questão de tempo. De muito pouco tempo. Mas era, na verdade, como se eles já estivessem fazendo sexo. Um dos casais estava na cuba. Na cuba! Ele era o cozinheiro. Sabem o cozinheiro, aquele negro de quase dois metros de altura, musculoso, braços grossos, traços másculos, narigão, bocão, olhos escuros e penetrantes?, perguntaram elas. Pois era o próprio. O cozinheiro. Ele já estava sem camisa. Com as calças, mas sem camisa. Com o peito cabeludo de fora. E sem sapato também. Ela era aquela inglesa chique, loirinha, mirradinha, de nariz arrebitado, que 
desfila aqui pelo convés carregada de ouro parecendo uma igreja barroca. Os senhores sabem quem é, não?, perguntaram as duas. Pois ela já estava com o vestido arregaçado. Bem arregaçado. Um vestido de seda vermelho, trespassado, com saia de pregas. Estava tão arregaçado que dava para ver sua roupa de baixo, sussurrou a Olivinha de panturrilha menos grossa. Um escândalo, arrematou a outra. Agora, os senhores não vão acreditar em quem estava lá se amassando com o imediato, disseram as Olivinhas. A senhora Andrade, responderam em uníssono depois de uma pausa que queriam dramática. Os senhores ouviram bem? A senhora Andrade! Quem diria, não? Estava lá com o imediato na mesa onde o cozinheiro corta os legumes e as carnes das nossas refeições. Isso mesmo: na mesma mesa em que o cozinheiro corta os legumes e as carnes das nossas refeições. Das nossas refeições! Um nojo! Ele estava sentado e a senhora Andrade em pé, encostada nele. Ou melhor, espremida contra ele. Menos mal que ele estava de calça. Já pensaram se ele estivesse com o traseiro nu?, perguntou a Olivinha de panturrilha mais grossa, baixando a voz quando pronunciou "traseiro". Seria horrível, respondeu a outra, mas fiquei imaginando onde ele teria se sentado antes de chegar ali. Ele podia ter se encostado na pia do banheiro do salão principal, que todo mundo usa, ou se sentado no chão do convés, exatamente no lugar em que Margarida faz suas necessidades, ou ainda numa das espreguiçadeiras em que uma das crianças, que estão sempre enjoando com o balanço do navio, tivesse vomitado. Nojento! Eles não precisavam estar sentados justamente na mesa em que o cozinheiro corta os legumes e as carnes. Poderiam estar em qualquer uma das tantas cadeiras da cozinha. Os senhores não fazem ideia da quantidade de cadeiras que há na cozinha. Poderiam ter usado qualquer uma delas. Mas não, eles preferiram macular a mesa em que o cozinheiro corta os legumes e a carne. Os legumes e a carne que a gente come todo dia! Sacrilégio! Eles não levam nem comida a sério! A senhora Andrade se esfregava muito no imediato. Muito. E o imediato, como o cozinheiro, estava sem camisa e sem sapatos. Ela estava tão grudada nele que não dava para ver seu rosto. Mas nós a reconhecemos pelo vestido. Aquele vestido azul, de cintura baixa, da década passada, que ela ajustou todinho para ficar na moda. Mas que não convenceu. Ah, não convenceu. A gente ia saindo de fininho, continuou a Olivinha de panturrilha menos grossa, quando ouvimos a voz da senhora Andrade.

- Meninas! Não vão embora, queridas! Fiquem aqui conosco. Entrem e aproveitem. A vida é uma só.

Ficar lá. Imaginem! Era só o que nos faltava! Preferimos ficar sem chá. Está certo que ainda não era uma suruba propriamente dita, mas seria. Temos certeza disso. Era evidente que eles começariam a fazer sexo. E trocariam os casais. Era óbvio. Só uma questão de tempo. Mas não esperamos para ver. Não mesmo. Voltamos correndo para o quarto com a chaleira. Com a chaleira vazia. Ficamos sem chá e sem sono. Não comentamos nada com nossa tia. Os senhores, por favor, não falem nada. Ela já é uma senhora de mais idade, cardíaca, pode ter um piripaque. Melhor não provocar. Isso fica entre nós. Será o nosso segredo. Pobre senhor Andrade. Um homem tão bom. Mas ele deve ter suas amantes. Outro dia, quando saíamos da sala de jantar, ele tascou um beliscão em nossos traseiros. Esse pessoal da primeira classe não tem mesmo moral. Sabemos que o senhor e a senhora Andrade não viajam mais de primeira classe. Mas já viajaram muito. Eles continuam sendo de primeira classe. Uma vez primeira classe sempre primeira classe. O mesmo vale para a classe turística. Não é uma questão de dinheiro. E o pessoal da primeira classe se diverte mais. Ah, se diverte! Quem não tem deus no coração parece se divertir bem mais do que quem tem. Mas eles se divertem agora. Quero ver depois. Quando acabar esta vida e vier a outra, a vida depois da vida. A vida de verdade. Aí nós vamos ver quem vai se divertir. As Olivinhas pararam de falar e ficaram sacudindo a cabeça em assentimento, aprovando com este gesto suas próprias palavras. O único problema, disse por fim a Olivinha de panturrilha grossa, é se não houver outra vida e a vida de verdade for esta aqui, a vida das surubas na cozinha.

\section{Referências}

BATAILLE, Georges. A conjuração sagrada. Tradução Fernando Scheibe. In: Boletim de Pesquisa - NELIC, v. 8, n. 12/13, p. 230-232, 2008.

BLANCHOT, Maurice. La communauté inavouable. Paris: Éditions De Minuit, 1983.

BOLAÑO, Roberto. Exilios. In: Entre paréntesis. Barcelona: Anagrama, 2006.

CALDERÓN DE LA BARCA, Pedro. La vida es sueño. Monólogo que se apresenta no fim da "Jornada segunda". Madrid: Akal, 1999.

FOUCAULT, Michel. As heterotopias. In: O corpo utópico, As heterotopias. Tradução Salma Tannus Muchail. São Paulo: N-1, 2013.

STERZI, Eduardo. A prova dos nove. Bauru: Lumme, 2008.

STIGGER, Veronica. Opisanie świata. São Paulo: Cosac Naify, 2013.

Recebido: $10 / 07 / 2018$

Aprovado: 13/10/2018

(D) VeronicA ANTONINE STIGGER < vastigger@faap.br>

Professora, Fundação Armando Álvares Penteado, São Paulo, SP.. 